\title{
Multiple Acyl-CoA Dehydrogenase Deficiency
}

National Cancer Institute

\section{Source}

National Cancer Institute. Multiple Acyl-CoA Dehydrogenase Deficiency. NCI Thesaurus. Code C84907.

A rare autosomal recessive inherited metabolic disorder caused by mutations in the ETFA, ETFB, or ETFDH genes. It is characterized by deficiency of either electron transfer flavoprotein (ETF) or electron transfer flavoprotein dehydrogenase (ET FDH). Clinical presentations include congenital abnormalities (brain and facial malformations), hypotonia, dilated cardiomyopathy, hepatomegaly, metabolic acidosis, hypoglycemia, and behavioral changes. 